\title{
Developing Optimization Modelling Methodology for Production Costs Generation

\author{
${ }^{1}$ Solovyova E.V., ${ }^{\text {,2}}$ Sekisov A.N., ${ }^{3}$ Gura D.A., ${ }^{4}$ Mikheev G.V., ${ }^{5}$ Kovtunenko M.G. \\ 1,3,4,5 Kuban State Technological University, Krasnodar, Moscovskaya Str, 2 \\ ${ }^{2}$ Kuban State Agrarian University, Krasnodar, Kalinina Str., 13 \\ Email: soloveisolovei008@yandex.ru,alnikkss@gmail.com,gda-kuban@mail.ru,mgstyle77@yandex.ru,di- \\ marin@list.ru
}

Received: 16th January 2020, Accepted: 31st January 2020, Published: 30th April 2020

\begin{abstract}
Based on the developed model and the conceptual scheme of production cost generation improvement, the technique is proposed that allows to optimize the work of the building complex enterprise cost mechanism by choosing the best option for the correlation of the levels of influence of production cost development factors on cost indicators and the levels of their manageability. The developed methodological mechanism to improve the functioning of the cost-education system in companies is of significant practical importance and is based on the conclusions of theoretical studies, as well as on the results of the analytical study of construction enterprise activities.
\end{abstract}

\section{Keywords}

Production Costs, Cost Optimization, Production Cost Development Factors, Manageability Levels, The Priorities of Economic Activity, Factor and Resulting Attributes.

\section{Introduction}

The proposed methodology for production cost generation improvement, developed on the basis of the company cost mechanism optimization modelling, has significant applied prospects for application, since it allows one to achieve in equal intervals of time with a fixed change of factor signs of increase within the set rate the decline level of costs per ruble of marketable products and the costs per unit of physical volume of marketable products in relation to the actual ones.

\section{Material and Methodology}

As the part of the methodology development to improve the process of production cost generation, they proposed the model for problem setting (1). During the indicated model development, the existing methods of statistical modeling were used $[10,12]$.

$$
Z=\sum_{a=1}^{k} g_{a} p_{a}+\sum_{j=1}^{l} g_{j} p_{j}+\sum_{u=1}^{m} g_{u} p_{u},
$$

with the corresponding limitations:

where $Z$ - the required level of production costs;

$$
\left.\begin{array}{l}
g_{a_{a} p_{a}} \equiv e_{q} \\
g_{j} p_{j} \equiv e_{y} \\
g_{u} p_{u} \equiv e_{o} \\
g_{a} p_{a} \equiv \beta_{q} \\
g_{j} p_{j} \equiv \beta_{y} \\
g_{u} p_{u} \equiv \beta_{o}
\end{array}\right\} e_{o}>e_{y} \ngtr e_{g} \geq|0,| \mid
$$

$g_{a}, g_{j}, g_{u}$ - the parameters characterizing the production costs from the quantitative aspect;

$p_{a}, p_{j}, p_{u}$ - the parameters characterizing production costs in terms of their cost;

$e_{q}, e_{y}, e_{o}-$ elasticity coefficients (relative comparable indicators of the relationship

strength between the variations of the effective and factor attributes), characterizing, the low, medium, and high level of influence of production cost development factors on cost indicators; 
$\beta_{q}, \beta_{y}, \beta_{o}-$ standardized regression coefficients (relative comparable indicators of the relationship tightness between the variations of the resultant and factor attributes), characterizing, respectively, the low, medium, and high level of controllability of production cost development factors;

$a=1,2, \ldots, k-$ the number of the parameters considered, related to the cost-effectiveness in the field of socio-economic sphere of enterprises and financial stability provision;

$j=1,2, \ldots, l-$ the number of considered parameters related to the cost-effectiveness of production in the field of material production and competitiveness provision;

$u=1,2, \ldots, m-$ the number of parameters under consideration related to the costeffectiveness of material production in the field of material production and transaction support;

$q=1,2, \ldots, r$ - the number of considered elasticity coefficients and the coefficients character-

izing the level of factor influence from the socio-economic sphere of activity of enterprises and financial stability provision on cost indicators and their level of controllability;

$y=1,2, \ldots, s-$ the number of considered elasticity coefficients and the coefficients character-

izing the level of influence of material production and competitiveness factors on cost indicators and their level of controllability;

$o=1,2, \ldots, v-$ the number of considered elasticity coefficients and the coefficients character-

izing the level of influence of material production factors and transaction support on cost indicators and their level of controllability.

In accordance with the abovementioned model, the problem of optimizing the level of production costs is solved by choosing the best option for correlation the levels of influence of production cost development factors on cost indicators and the levels of controllability within the established limits. The validity of this statement is based on the conclusions of theoretical studies $[15,16,17]$, and its feasibility is based on the results of an analytical study of company activities and the environment of their functioning $[1,2,18,19]$.

It should be noted that the ratio of the levels of influence of production cost development factors on cost indicators and levels of manageability within the established limits is conditioned by the need to achieve a high level of influence by material production and transaction support factors (they have a high degree of significance in the results of economic activity), medium level of influence by the factors of material production and competitiveness provision (they carry out economic and organizational support of the factors with a high level of influence) and a low level of influence by the factors of the socio-economic sphere and financial stability provision (they are accompanied by the factors with a high level of influence, which is explained by the low degree of their significance in economic activity results).

\section{Result \& Discussion}

Presented methodology makes it possible to identify specific paths, determine and evaluate the specific economic effect of production cost formation process improvement clearly, which enables enterprises to use rationally the available resources of economic activity and manage effectively the operation of the cost mechanism. This is true both for the current activities of companies and for the implementation of various projects within the construction complex.

The presented model is focused on specific business result achievement. In turn, for a practical solution to the problem stated in the framework of this model, we have developed the methodology to improve the process of production cost generation. It should be noted that the need to develop this methodology is determined by the lack of an appropriate methodological base at the moment. Existing methodological approaches $[4,5,6,7,8,9$, $11,12,13]$, aimed at cost mechanism operation improvement, do not allow to solve the problem of production cost level optimization by choosing the best option for the ratio of influence levels concerning the factors of production cost development on cost indicators and the levels of controllability.

The proposed methodology is developed on the basis of the concept improving the process of production cost generation, shown in Figure 1. This scheme reflects the totality of sequential actions that allows you to manage the operation of the cost mechanism and aimed at an optimal level of production cost achievement both in the whole enterprise and in certain areas of its activities. 


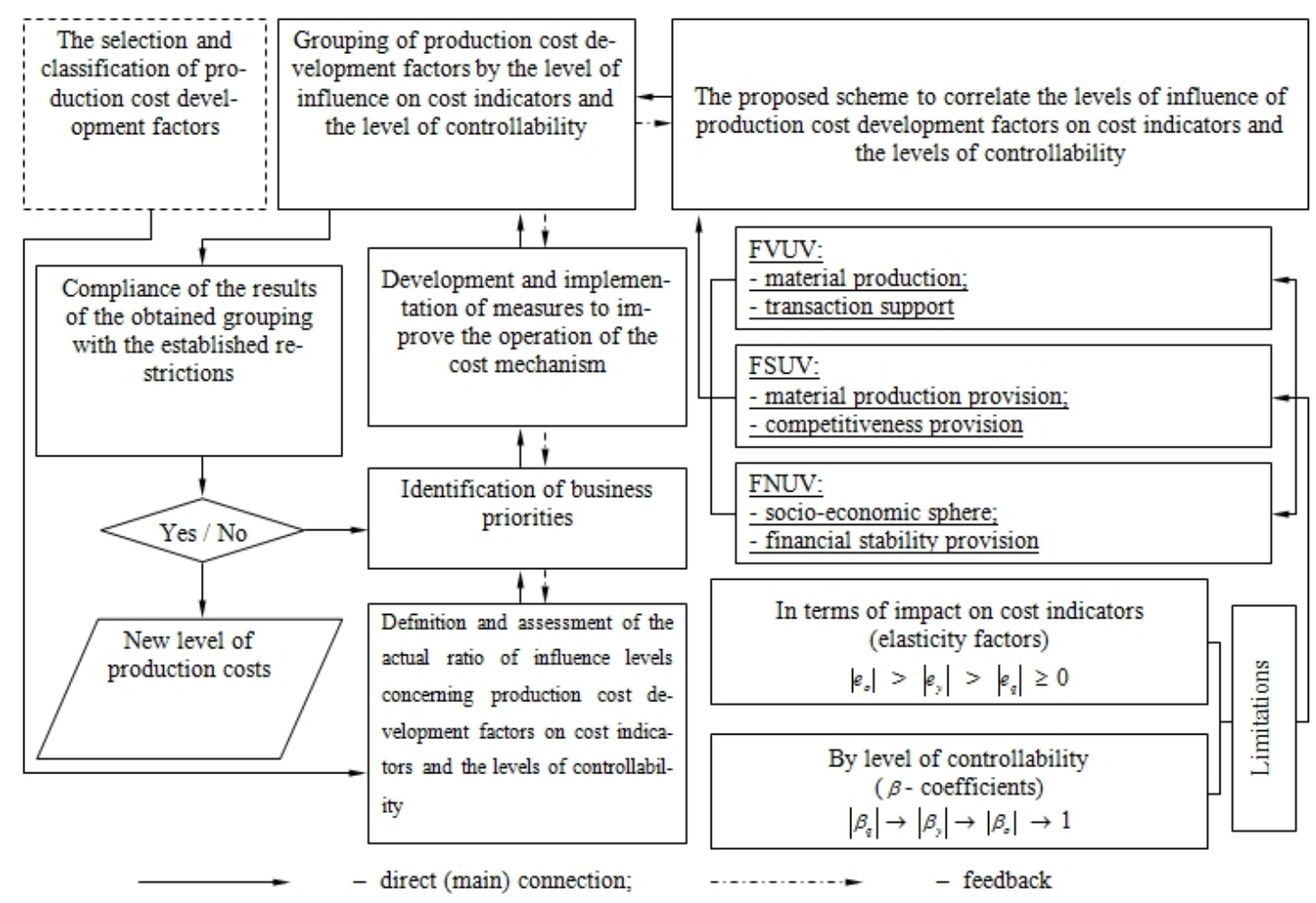

Figure 1: Schematic Diagram of Production Cost Improvement

According to Figure 1, the use of this technique is associated with the need for selection and classification of production cost development factors. The selection of these factors is carried out on the basis of the possibility to evaluate the impact of each of them on the process of cost formation in the framework of the existing statistical reporting and the level of their influence, both actual and expected, on the cost indicators.

The factors of production cost formation were classified by us in the main areas of enterprise activity. The results of this classification are presented in Figure 2.

As can be seen from Figure 1, this classification is the basis for determination and assess of the actual ratio of influence level concerning the factors of production cost development on cost indicators and the levels of controllability. The definition and evaluation of this ratio includes the following sequence of actions:

1. The calculation of generalized indicators concerning the effectiveness of enterprises and generalized indicators of costs.

Analysis of production system results.

Structural analysis of production costs in accordance with the proposed classification of production cost development elements (Figure 3).

2. Calculation of paired and multifactor correlation models that reflect the interconnection of factor and productive attributes (the indicators characterizing the influence of individual factors on the formation of production costs are used as factor indicators; generalizing indicators of production costs are used as effective indicators).

The assessment of the cross-correlation of factor attribute significance by a correlation matrix.

Evaluation of factor and effective sign correlation reliability. 


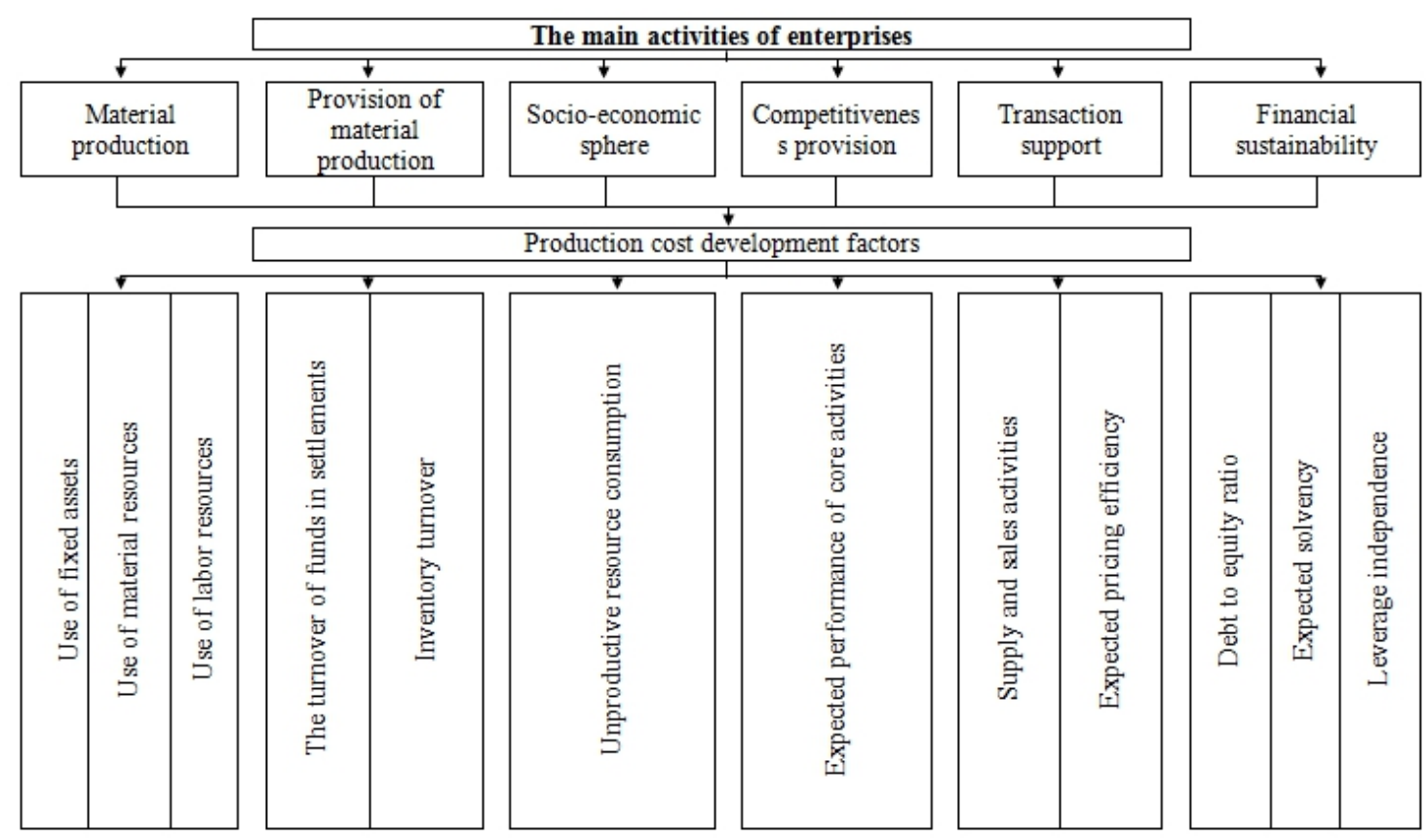

Figure 2: Classification of Production Cost Development Factors

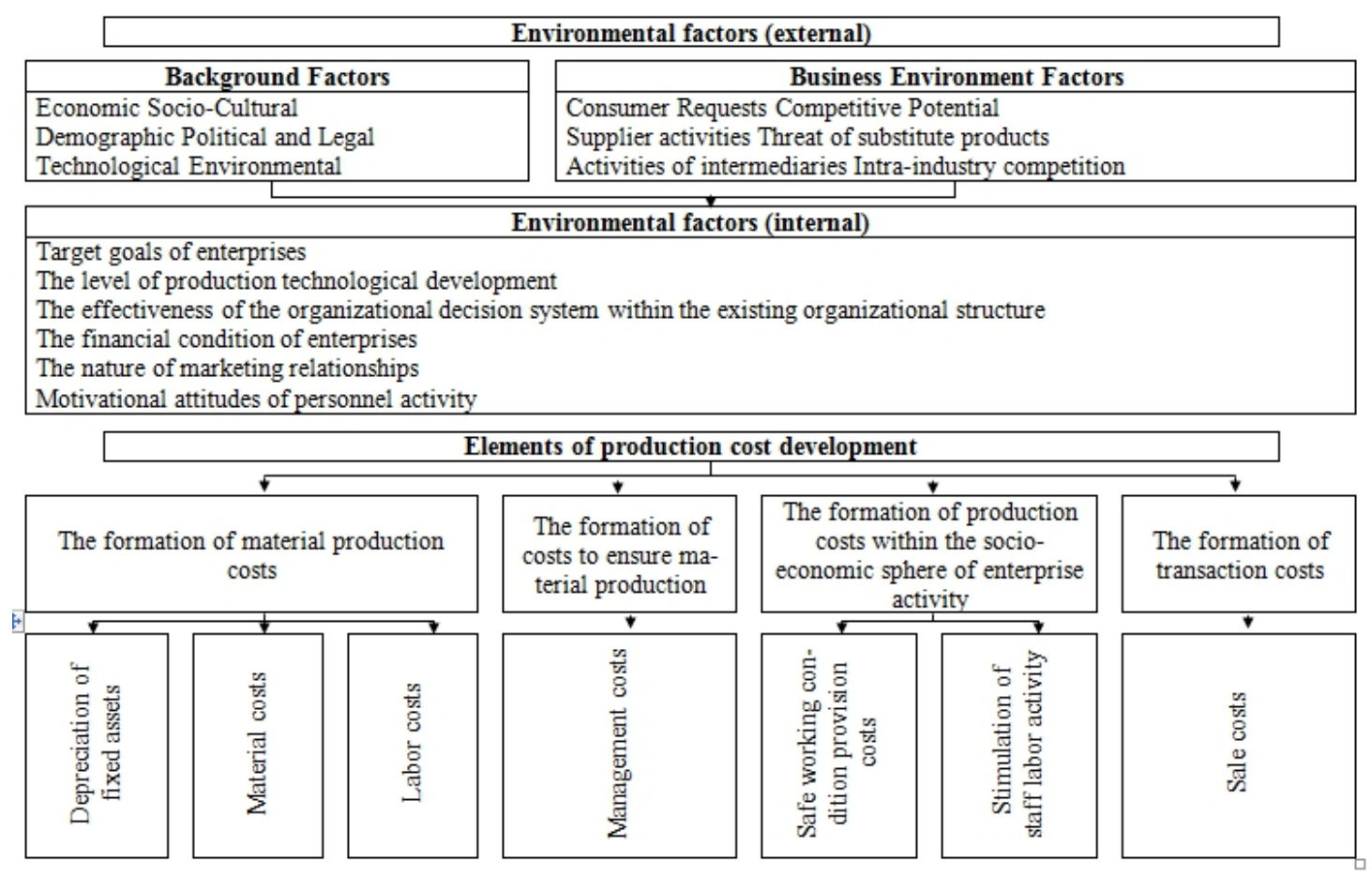

Figure 3: Classification of Production Cost Development Elements 
In general, they are characterized by the parameters indicative of their relevance: the value of the multiple correlation coefficient is significant (the actual size of the Student t-test is in all cases higher than the table at the confidence level of $\mathrm{P}=0.05$ ) and exceeds - 0.30 units (the relationship is not weak), the actual value of the Fisher F-criterion at the significance level of $\alpha=0,05$ and corresponding degrees of freedom exceed its theoretical value. The analysis of the correlation matrix indicates the insignificance of the mutual correlation of factor features, since in all the presented cases the pair correlation coefficient does not exceed its critical value - 0.85 units.

3. Calculation within the framework of multifactorial models of elasticity coefficients $e_{1 i(2 i)}$ and standardized regression coefficients $\beta_{1 i(2 i)}$ for each specific factor trait.

The grouping of production cost development factors on the basis of the given criteria according to the actual level of their influence on the cost indicators in accordance with the value $e_{1 i(2 i)}$ and the actual level of controllability in accordance with the value $\beta_{1 i(2 i)}$ (it is performed using existing statistical grouping methods).

The results of the grouping reflect the actual correlation of influence levels concerning production cost development factors on the indicators of costs and the levels of controllability (Figures 4 and 5).

4. Evaluation of the actual ratio concerning the influence levels of production cost development factors on cost indicators and the levels of manageability from the point of view of its compliance with the proposed scheme of the correlation concerning the levels of influence of production cost development factors on cost indicators and levels of controllability, presented in Figure 1, in the framework of the established restrictions (there is a need to find the ways to achieve it in the absence of this correspondence).

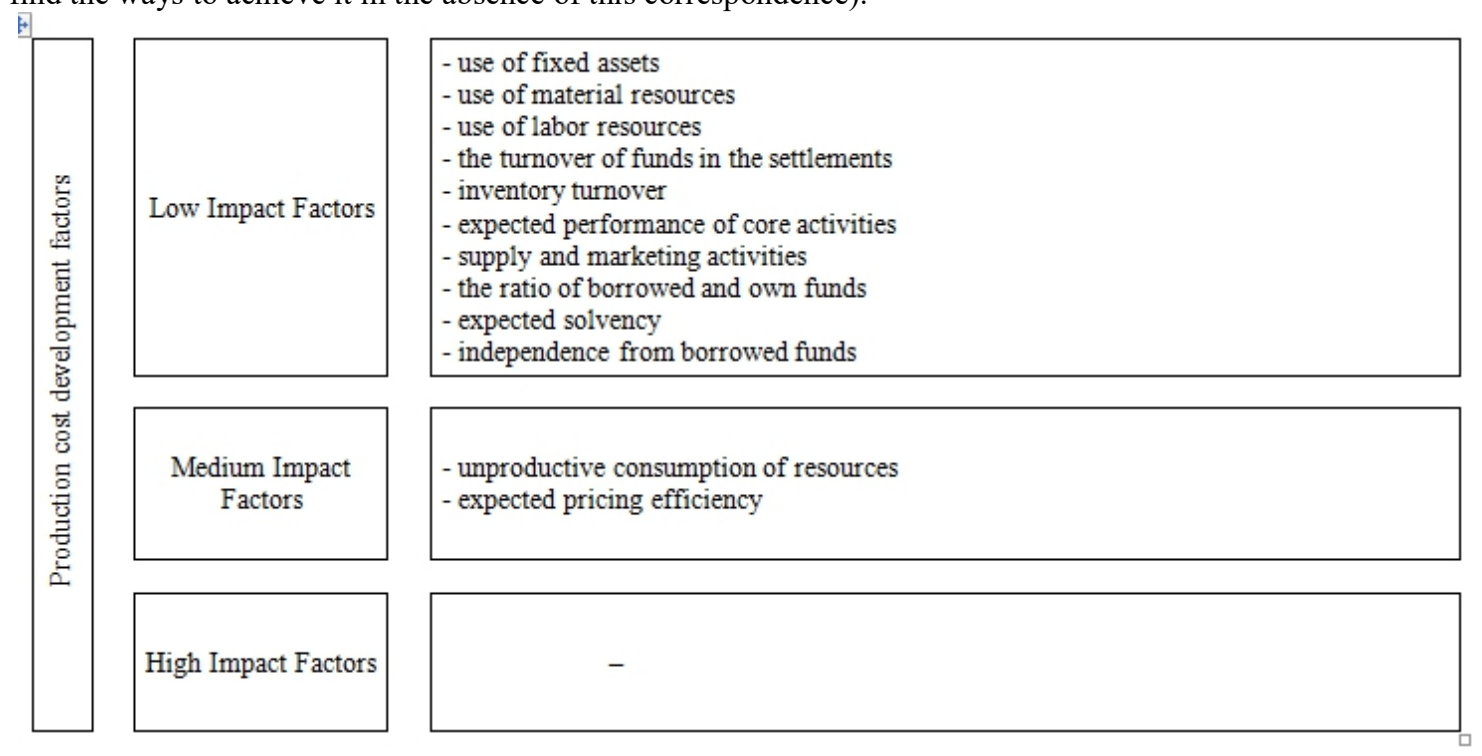

Figure 4: The Features of Production Cost Factor Development Influence on the Result of Cost Formation 


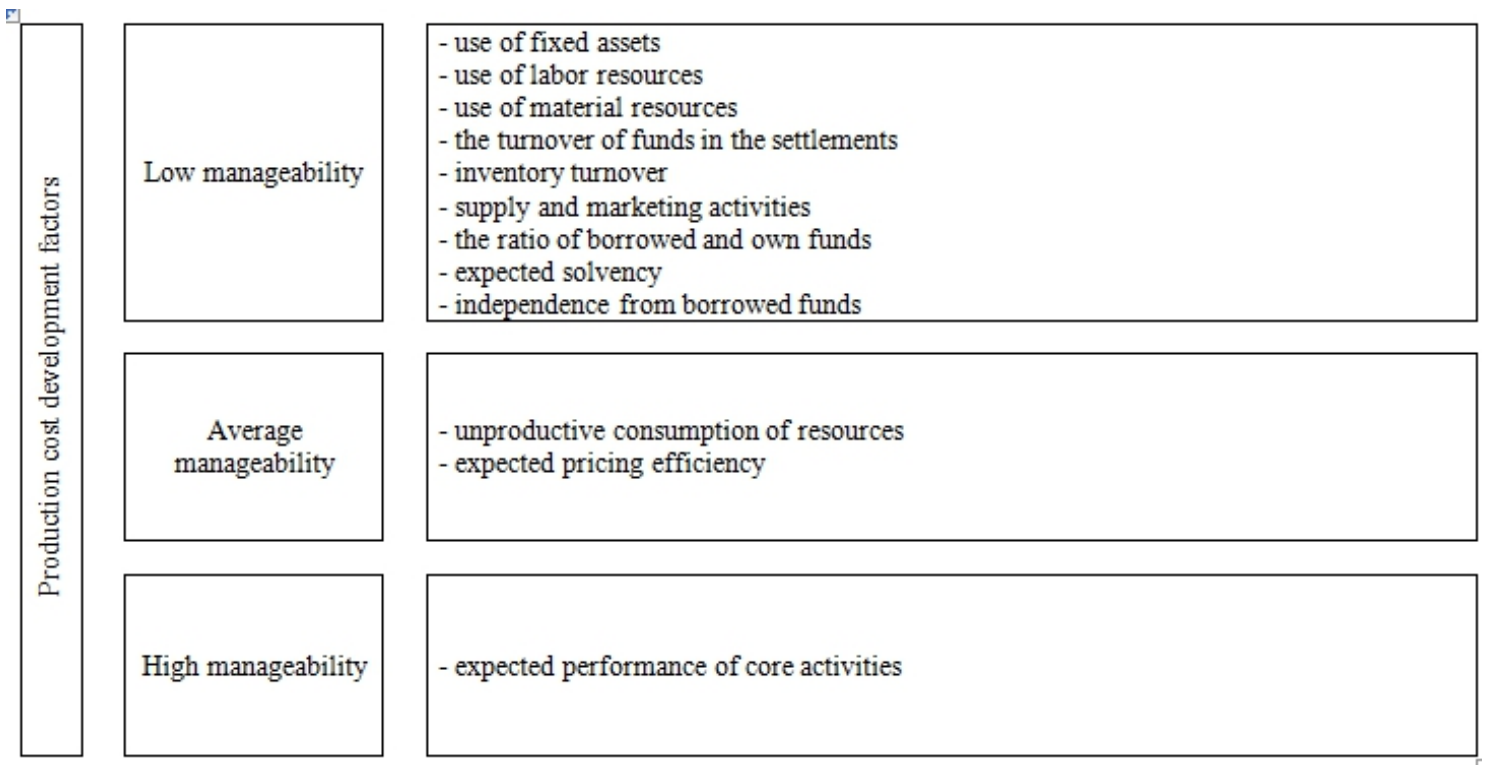

Figure 5: The Features of Production Cost Formation Factor Controllability at the Enterprises of the Construction Complex

The analysis results for state, cost formation possibility assessment, the assessment of the characteristics of production cost factor formation influence on cost indicators and the particularities of their manageability within the industry allow us to conclude that it is advisable to transform the costly policy of production systems aimed at the abovementioned compliance achievement.

For this, as can be seen from Figure 1, within the framework of the proposed methodology, there is a need to identify the priorities of economic activity, which allow to change the work of the costly mechanism in a specified way.

Comparing the actual existing correlation of influence levels concerning the production cost factor formation on cost indicators and the levels of controllability with the proposed scheme, we identified the following main priorities of economic activity according to Figure 6:

1. Optimization of production asset structure by increasing their active part, the level of production mechanization and automation increase, which helps to reduce the complexity of production processes.

Production material consumption reduction due to the introduction of progressive technologies and the use of modern effective components that are the part of the building complex products, which can improve its technical and economic characteristics, and which makes it possible to use the resources of production system rationally.

Labor productivity increase due to staff production activity stimulation, the reduction of the existing gap between the amount of labor costs and the value of labor productivity, which contributes to the emergence of positive motivational attitudes among the employees of enterprises and allows to increase the overall efficiency of labor resource use. 


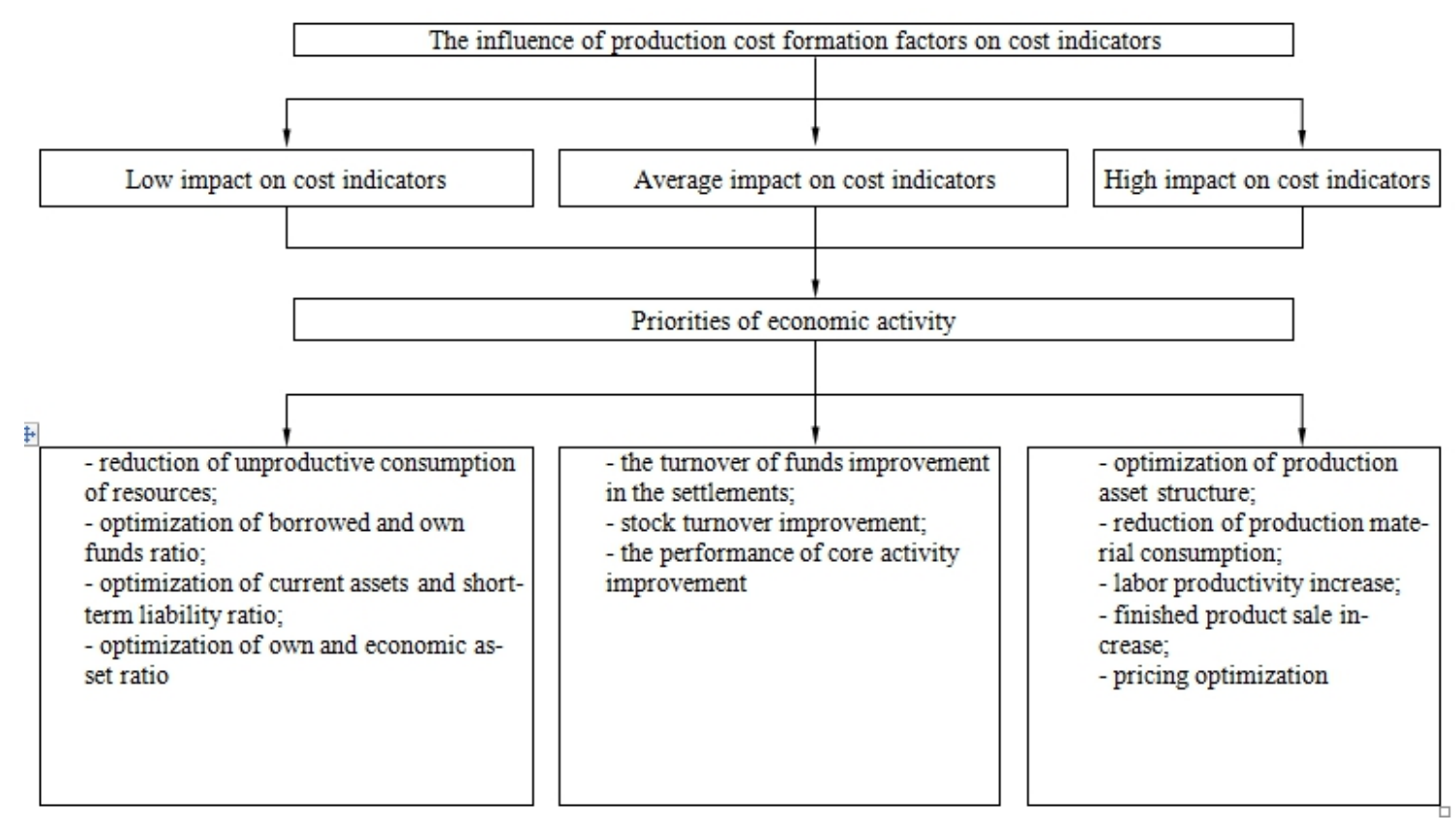

Figure 6: Distribution of Business Priorities in Accordance with the Proposed Scheme for the Correlation of Influence Levels Concerning the Factors of Production Cost Development on Cost Indicators

The increase of finished product sale and pricing optimization through an active transaction policy, which creates the conditions for the further development of production infrastructure and the maximum possible development of potential sales markets.

Orientation of the construction industry enterprises to the indicated priorities of economic activity allows to increase the actual level of material production factor and transaction provision influence on cost indicators to specified rates and improve their manageability in accordance with the previously established restrictions (Figure 1).

2. Improvement the turnover of funds in the settlements based on the optimization of mutual settlements with debtors, which creates the conditions for fund use efficiency increase.

Inventory turnover improvement by optimizing the management process and the technological structure of production, which generally contributes to production activity efficiency increase at the enterprises of the construction complex.

Improvement the effectiveness of core business through the use of internal reserves of enterprises in the framework of material production, ensuring transactions and material production, as well as by improving the overall financial situation of production systems, which generally improves the competitiveness of production.

Orientation of the construction industry enterprises to the indicated priorities of economic activity makes it possible to increase the actual level of influence concerning the factors ensuring material production and competitiveness on cost indicators to specified amount and to improve their manageability in accordance with previously established restrictions (Figure 1).

3. A substantiated reduction of unproductive consumption of resource amount due to the optimization of the social infrastructure of enterprises, helps to improve the general climate in production, increase labor productivity, and the efficiency of core activities and the efficiency of the cost mechanism in general.

Optimization of borrowed and own funds, current assets and short-term liabilities, own and economic assets on the basis of bringing them in line with existing normal restrictions, which allows to increase the financial stability of production systems and generally creates conditions to increase the efficiency of financial resource use.

Orientation of the construction industry enterprises to the indicated priorities of economic activity makes it possible to lower the actual level of influence concerning the socio-economic factors and ensure financial stability of cost indicators to specified values and improve their manageability in accordance with previously established restrictions (figure 1).

The business priorities identified in the proposed methodology, according to Figure 1, are the basis for the development and implementation of specific practical measures to improve the work of the cost mechanism. According to the results of the implementation of measures related to the improvement of cost formation, within the framework of the proposed methodology, according to Figure 1, there is a need to assess a new state of the cost mechanism, characterized by a different ratio concerning the influence level of production cost formation 
factor on cost indicators and the levels of controllability relative to the current ones. Assessing the results of the obtained group from the point of view of their correspondence to the proposed scheme of influence level correlation concerning production cost factor formation on cost indicators and manageability levels within the established limits, it can be concluded whether a new optimal level of production costs is reached or not. If the obtained grouping results do not correspond to the proposed scheme, it is impossible to talk about reaching such a level. In this regard, there is a need to review the priorities of economic activity with the subsequent adjustment of measures to improve the work of the cost mechanism. Otherwise, the improvement of production cost generation process can be considered successful, as it becomes possible to obtain the desired result - a new optimal level of costs.

\section{Conclusions}

Thus, our proposed methodology to improve the process of production cost formation, developed within the framework of the corresponding model (formula (1)) and based on the previously presented schematic diagram (Figure 1), allows as a whole to achieve increase by a given amount of the rate of decrease in the level of costs per ruble of commodity products and the costs per unit of physical volume of commodity products in relation to the actually possible one at equal intervals with a fixed change in factor attributes. Moreover, such changes are accompanied by a significant improvement in the overall economic situation of enterprises within the industry.

\section{Acknowledgements}

The study was financially supported by the Russian Foundation for Basic Research and the Administration of the Krasnodar Territory of the Russian Federation within the research project No. 19-48-233020

\section{References}

1. Popov R.A., Shipilova N.A., Sekisov A.N., Soloveva E.V., Gura D.A. Innovative development of construction in russia: economics, technologies, management. Amazonia Investiga. 2019. V. 8. № 19. pp. 653-663 (Access mode: https://www.udla.edu.co/revistas/index.php/amazonia-investiga/article/view/1408/pdf).

2. Mikheev G.V., Sekisov A.N., Gura D.A., Abazyan A.G., Kuznetsova O.A. Economic and marketing adaptation of business processes in the modern Russian real estate market. Revista Inclusiones. 2019. V. 6. № 2. pp. $119-124$

http://www.revistainclusiones.com/gallery/9\%20vol\%206\%20num\%202\%202019abriljunioasiaeuropaasia19inc 1.pdf).

3. Sekisov A.N., Degtyareva O.G., Samsonova N.V., Grigoryan M.N. Development of the Methods Improving the Production Costs Formation Process. В сборнике: International Conference on Construction and Architecture: theeory and practice of industry development 2018. 2018. pp. 1210-1213 (Access mode: https://www.scientific.net/MSF.931.1210, doi:10.4028/www.scientific.net/MSF.931.1210).

4. Ivanov LA., Borisova O.N., Muminova S.R. The inventions in nanotechnologies as practical solutions. Part I. Nanotehnologii v stroitel'stve $=$ Nanotechnologies in Construction. 2019, Vol. 11, no. 1, pp. 91-101. DOI: 10.15828/2075-8545-2019-11-1-91-101.

5. Ivanov L.A., Demenev A.V., Muminova S.R. The inventions in nanotechnologies as practical solutions. Part II. Nanotehnologii v stroitel'stve $=$ Nanotechnologies in Construction. 2019, Vol. 11, no. 2, pp. 175-185. DOI: 10.15828/2075-8545-2019-11-2-175-185.

6. Ivanov LA., Prokopiev P.S. The inventions in nanotechnologies as practical solutions. Part III. Nanotehnologii $\mathrm{v}$ stroitel'stve $=$ Nanotechnologies in Construction. 2019, Vol. 11, no.3, pp. 292-303. DOI: 10.15828/2075-8545-2019-11-3-292-303.

7. Ivanov LA., Prokopiev P.S. The inventions in nanotechnologies as practical solutions. Part IV. Nanotehnologii $\mathrm{V}$ stroitel'stve $=$ Nanotechnologies in Construction. 2019, Vol. 11, no. 4, pp. 447-457. DOI: 10.15828/2075-8545-2019-11-4-447-457.

8. Kozina T.A. Methodological approaches in the control system of production costs. - M.: AgroNIITEIPP, 1994. - Issue. 1, 1 - 28. - 28 p.

9. Methods of production cost accounting and analysis. / A.F. Aksenenko, V.V. Novikov, V.I. Sidorov, etc.; Ed. by A.D. Sheremet. - M.: Finance and statistics, 1987. - 208 p.: Ill.

10. Guidelines for long-term plan optimization in respect of the building materials industry / Edited by the Dr. of Econ. D.M. Kazakevich. - M.: Stroyizdat, 1974. - 413 p.

11. Methodological recommendations for labor cost reduction in the factory production of structures and the construction of large-panel residential buildings. - M.: VNIPI of labor in the construction of the Gosstroy of the USSR, 1980. - $53 \mathrm{p}$.

12. Modeling of production processes at the enterprise. New in the management of production abroad: Translation from German. / Edited by V. M. Savinkov. - M.: Progress, 1972. - Coll. 4. - 333 p.

13. Nikolaeva S.A. Features of cost accounting in market conditions: "direct costing" system: Theory and practice. - M.: Finance and Statistics, 1993. - 128 p.: Ill. 
14. Petrova V.I. System analysis of cost. - M.: Finance and Statistics, 1986. - 175 p.

15. Sekisov A.N. The role of production cost generation process in production systems // Economics and Entrepreneurship. 2015. No. 7 (60). pp. 503-507.

16. Sekisov A.N. Theoretical aspects of production cost development in a market economy // Bulletin of the Adygea State University. Series 5: Economics. 2012. No. 3 (104). pp. 178-187.

17. Sekisov A.N., Savenko A.A. Prerequisites for improving the process of production cost development. // Economics and Entrepreneurship. 2016. No. 10-3 (75-3). pp. 467-472.

18. Volkov A. N.; Leonova A. N.; Karpanina E. N., Gura D.A. Energy performance and energy saving of lifesupport systems in educational institutions // journal of fundamental and applied sciences. 2017, Vol: 9 №: SI 2, pp. 931-944.

19. Karpanina E. N.; Leonova A. N.; Sirotina O. V., Gura D.A. Analytical Aspects of Special Purpose Metal Structures Design // Revista publicando 2018 Vol: 5 №: 14 pp. 735-743. 